\title{
Role of polyenes in the coloration of cultured freshwater pearls
}

\author{
STEFANOS KARAMPELAS ${ }^{1,2, *}$, EMMANUEL FRITSCH$^{2}$, JEAN-Yves MEVELLEC $^{2}$, SPYROS SKLAVOUNOS $^{1}$ \\ and TRIANTAFYLLOS SOLDATOS ${ }^{1}$ \\ ${ }^{1}$ School of Geology, Department of Mineralogy - Petrology - Economic Geology, Aristotle, \\ University of Thessaloniki, 54124 Thessaloniki, Greece \\ *Corresponding author, e-mail: steka@physics.auth.gr and stefanos.karampelas@cnrs-imn.fr \\ ${ }^{2}$ Université de Nantes, Nantes Atlantique Universités, CNRS, Institut des Matériaux Jean Rouxel (IMN), \\ 2 rue de la Houssinière, BP 32229, 44322 Nantes Cedex 3, France
}

\begin{abstract}
The exact nature of pigments present in cultured freshwater pearls is still not well known. We examined 21 untreated cultured freshwater pearls from Hyriopsis of typical colors by diffuse reflectance UV-Vis-NIR and Raman scattering measurements, at high resolution. The objective was to establish the relation between color and the nature of the pigment mixture in pearls, using strictly non-destructive methods. All natural color samples show the two major Raman resonance features of unmethylated (unsubstituted) polyenes, not carotenoids. Their general chemical formulae are R-(-CH=CH$)_{N}-\mathrm{R}^{\prime}$ with $N=6$ to 14 and they give absorptions from violet to yellow-green. Each color is due to a mixture of pigments, not a single pigment. Different colors are explained by different mixtures. Each pigment identified by Raman spectroscopy can be related to a specific absorption with apparent maximum in the range $405-568 \mathrm{~nm}$, thus absorbing from violet to yellow-green. This is the first study of the precise relation between Raman and diffuse reflectance spectra of cultured freshwater pearls.
\end{abstract}

Key-words: pearl, non-destructive spectroscopy, pigments, unmethylated polyenes.

\section{Introduction}

The aim of this work is to establish the relation between color and the nature of the pigment mixture in cultured freshwater pearls using non-destructive methods, such as diffuse reflectance UV-Vis-NIR spectroscopy and Raman resonant or (near-resonant) scattering (RRS), at high resolution. This subject rises in importance as the demand for colored pearls has grown over the past three decades. Pearls are composites of calcium carbonate, chiefly aragonite, and organic material, deposited in concentric layers. However, the exact nature of pigments present in such gem materials is still not well known. Previous studies have established that Raman scattering is useful to detect pigments in natural saltwater (Urmos et al., 1991) and cultured freshwater pearls (Li \& Chen, 2001; Fengming et al., 2003). The pigments have been identified as carotenoids. More recent studies have shown that the color of pearls is due to a mixture of short unsubstituted polyenes, not carotenoids (Karampelas et al., 2006 and 2007).

\section{Background}

Pearls are biominerals secreted in the interior of living mollusks (phylum Mollusca) with or without human intervention. However, not all pearls are desirable but a few species of mollusks have the ability to produce pearls which are iridescent, and represent the typical commercial pearl product (Hänni, 1999). Pearls are natural or cultured. Natural pearls are secreted accidentally in a mollusk without any human intervention. Cultured pearls are formed in mollusks by human intervention, either in freshwater or saltwater. The vast majority of pearls found today in the market are cultured. Moreover, only a small number of mollusk species are used for large scale commercial cultivation. For cultured saltwater pearls these are the bivalves Pinctada margaritifera, Pinctada fucata (martensii) (producing so-called akoya cultured pearls), Pinctada maxima (producing so-called South Sea cultured pearls), Pteria sterna, and more rarely the gastropod Haliotis iris (producing so-called abalone cultured pearls). For freshwater pearls, the following bivalves are used for cultivation: Hyriopsis schlegeli (H. schlegeli) (still known in the market as Biwa cultured pearls even if they are not all cultured at Lake Biwa in Japan), Hyriopsis cumingi (H. cumingi) and the hybrid Hyriopsis schlegeli x cumingi.

Raman spectroscopy is useful to identify the pigments in cultured freshwater pearls. However, in other cases Raman spectroscopy is not always useful for pearl pigment detection, for example no pigment signal is obtained for the yellow "golden" colored pearls from the bivalve Pinctada maxima. 
The present study is done on cultured freshwater pearls. They occur in five main hues, i.e. white, grey, pink, orange and purple. However, various combinations of hue, tone and saturation yield a broad range of color appearances.

Polyenes (polyacetylenes) are polyunsaturated organic compounds that contain one or more sequences of alternating single and double carbon-carbon bonds, named a polyenic chain. Carotenoid molecules contain a polyenic chain, however there are four additional methyl groups substituted on this chain. Pigments containing polyenic chains are widespread in nature, for example in phytoplankton (Hoskins \& Alexander, 1977), coral polyps and mollusk shells (Fox \& Wilkie, 1970; Merlin \& Delé-Dubois, 1983; Merlin, 1985; Merlin \& Delé-Dubois, 1986; Vershinin, 1996; Barnard \& De Waal, 2006; Hedegaard et al., 2006), vegetables (tomatoes, carrots etc.; Withnall et al., 2003), bird feathers (Stradi et al., 1995, 1996, 2001a and b; Veronelli et al., 1995), human retina (Ermakov et al., 2005), etc. The vast majority of these pigments belong to the carotenoid family. It is therefore understandable that, when the pigment is not a carotenoid, it may still be reported as such. This is the case also for coloring agents in natural saltwater (Urmos et al., 1991) and cultured freshwater pearls of various colors (Li \& Chen, 2001; Fengming et al., 2003), in which a signal due to unsubstituted polyenes was detected, but was interpreted as due to carotenoids.

As early as 1882, Krukenberg recognized that parrot feathers contain pigments other than carotenoids, and named them psittacofulvins. These pigments differed from the widely distributed carotenoids in their chemical reactivity and solubility (Stradi et al., 2001b). More recently, Raman spectroscopy has shown that these pigments are unsubstituted (unmethylated) polyenes (Veronelli et al., 1995). Similar pigments have been known to color also some coral polyps (i.e., Corallium rubrum; Merlin \& Delé-Dubois, 1986), some molluskan shells (Barnard \& De Waal, 2006; Hedegaard et al., 2006) and cultured freshwater pearls (Karampelas et al., 2006 and 2007). Stradi et al. (2001b) observed that the color of parrot feathers of Ara macao is due to a mixture of at least four unsubstituted (unmethylated) polyenes. Recent Raman studies have shown that the color of cultured freshwater pearls of the Hyriopsis genus is also due to a mixture of short unsubstituted polyenes (Karampelas et al., 2006 and 2007).

It has been shown that the Raman spectra of polyenes exhibit strikingly intense features because of the existence of delocalized $\pi$-electrons, which may induce a resonance under visible wavelength excitation (Veronelli et al., 1995; Withnall et al., 2003). Two strong Raman resonant (RR) bands, due to polyenic chains, occur in the 1100-1200 and 1450-1600 $\mathrm{cm}^{-1}$ ranges. These bands correspond respectively to the carbon-carbon stretching vibration $\left(v_{2}\right)$ of a $\mathrm{C}-\mathrm{C}$ single bond (coupled to $\mathrm{C}-\mathrm{H}$ inplane bending modes), and to that of a $\mathrm{C}=\mathrm{C}$ double bond $\left(v_{1}\right)$ in a polyenic chain (Saito et al., 1983; Okamoto et al., 1984). The exact position of these bands is dependent on the length of the chain (Schügerl \& Kuzmany, 1981; Schaffer et al., 1991; Barnard \& De Waal, 2006). For carotenoids, which contain methyl groups in their polyenic chain, the position of the $v_{2}$ vibration is shifted about 20 $\mathrm{cm}^{-1}$ towards higher energy compared to polyenic chains without $\mathrm{CH}_{3}$ (Okamoto et al., 1984). The intensity of these bands is strongly enhanced over those not due to the polyenic chain. This enhancement is due to the coupling of electronic and vibrational transitions. Thus, polyenes can be easily studied without interference from other, nonresonant products, even in systems as complex as biological materials (Merlin \& Delé-Dubois, 1986). In solutions this kind of pigments may be detected at very low concentrations (detection limit of about $10^{-8} \mathrm{M}$; Hoskins \& Alexander, 1977).

Ermakov et al. (2005) attribute $C_{2 h}$ point group symmetry to polyenes. Their absorption is caused by electric dipole-allowed transitions of the molecule's conjugated $\pi$ electrons from the $1^{1} \mathrm{~A}_{\mathrm{g}}$ singlet ground state to the $1^{1} \mathrm{~B}_{\mathrm{u}}$ singlet excited state. Optical excitation within the absorption bands leads to weak luminescence. By analogy with the well studied $\beta$-carotene, the extremely low quantum efficiency of polyenes' luminescence (peaking at $530 \mathrm{~nm}$ ) is caused by the existence of a second singlet state, a $2^{1} \mathrm{~A}_{\mathrm{g}}$ state, which lies below the $1^{1} \mathrm{~B}_{\mathrm{u}}$ state. Following optical excitation of the $1^{1} \mathrm{~B}_{\mathrm{u}}$ state, the energy relaxes rapidly (within approximately $200-250 \mathrm{fs}$ in $\beta$-carotene) by nonradiative transitions to the lower $2^{1} \mathrm{~A}_{\mathrm{g}}$ state, from which electronic emission is symmetry forbidden. Their extremely weak $1^{1} \mathrm{~B}_{\mathrm{u}} \rightarrow 2^{1} \mathrm{~A}_{\mathrm{g}}$ luminescence and the absence of the $2^{1} \mathrm{~A}_{\mathrm{g}} \rightarrow 1^{1} \mathrm{~A}_{\mathrm{g}}$ transitions allow one to measure the RR spectra response of the molecules without interfering with luminescence signals. This combination of properties makes these molecules exceptionally easy to detect by Raman scattering. Moreover, the position of the maximum absorption $\left(\lambda_{\max }\right)$ is mainly a function of the length of the conjugated double-bond chromophore. Their energy gap between the highest occupied molecular orbital (HOMO) and lowest unoccupied molecular orbital (LUMO) is generally small (e.g., for a polyene in a solution with $N>3$ the energy gap is <4.5 eV; Schaffer et al., 1991; Heller et al., 1995). The first allowed electronic transition may occur in the visible region and give rise to color (Salares et al., 1977; Schaffer et al., 1991; Heller et al., 1995; Veronelli et al., 1995).

\section{Materials and methods}

This study was carried out on 19 colored untreated cultured freshwater pearls from $H$. cumingi and $H$. schlegeli covering a wide range of typical colors for this material and two white colored pearls from $H$. cumingi (Table 1 ). The samples are borrowed from reputed commercial sources (see Acknowledgements). As for all gems, the methods used to study the samples must be non-destructive. For this study, Raman scattering and UV-Vis-NIR diffuse reflectance spectra were acquired.

Diffuse reflectance spectra of all the samples were obtained at the IMN (Institut des Matériaux Jean Rouxel, France), for the 250-1600 nm range with a Cary 5G ultraviolet/visible/near-infrared (UV-Vis-NIR) spectrometer 
Table 1. Color range and homogeneity as well as mollusk species of naturally colored cultured freshwater pearls studied.

\begin{tabular}{|c|c|c|}
\hline $\begin{array}{l}\text { Sample } \\
\text { number }\end{array}$ & $\begin{array}{l}\text { Color description and } \\
\text { distribution }\end{array}$ & Mollusk \\
\hline SK56 & White-cream (homogeneous) & H. cumingi \\
\hline SK57 & White-cream (homogeneous) & H. cumingi \\
\hline SK58 & $\begin{array}{l}\text { Orange-slight grey } \\
\text { (homogeneous) }\end{array}$ & H. cumingi \\
\hline SK59 & $\begin{array}{l}\text { Orange-slight grey } \\
\text { (homogeneous) }\end{array}$ & H. cumingi \\
\hline SK60 & $\begin{array}{l}\text { Pink-grey "light pink" } \\
\text { (homogeneous) }\end{array}$ & H. cumingi \\
\hline SK61 & $\begin{array}{l}\text { Pink-grey "light pink" } \\
\text { (homogeneous) }\end{array}$ & H. cumingi \\
\hline SK83 & Orange (inhomogeneous) & H. cumingi \\
\hline SK84 & Violet-grey (inhomogeneous) & H. cumingi \\
\hline SK85 & $\begin{array}{l}\text { Grey-little violet } \\
\quad \text { (inhomogeneous) }\end{array}$ & H. cumingi \\
\hline SK86 & $\begin{array}{l}\text { Pink-grey "light pink" } \\
\text { (inhomogeneous) }\end{array}$ & H. cumingi \\
\hline SK87 & Violet-grey (inhomogeneous) & H. cumingi \\
\hline SK88 & Violet-grey (inhomogeneous) & H. cumingi \\
\hline SK89 & Violet-grey (homogeneous) & H. cumingi \\
\hline SK90 & Violet-grey (homogeneous) & H. cumingi \\
\hline SK91 & Grey (homogeneous) & H. cumingi \\
\hline SK92 & Grey (homogeneous) & H. cumingi \\
\hline SK116 & Slight yellow (homogeneous) & H. schlegeli \\
\hline SK117 & $\begin{array}{l}\text { Slight purple-grey "light } \\
\text { purple" (homogeneous) }\end{array}$ & H. schlegeli \\
\hline SK118 & $\begin{array}{l}\text { Pink-grey "light pink" } \\
\text { (homogeneous) }\end{array}$ & H. schlegeli \\
\hline SK119 & $\begin{array}{l}\text { Pink-grey "light pink" } \\
\text { (homogeneous) }\end{array}$ & H. schlegeli \\
\hline SK120 & $\begin{array}{l}\text { White-very light grey } \\
\text { (homogeneous) }\end{array}$ & H. schlegeli \\
\hline
\end{tabular}

fitted with a Varian diffuse reflectance accessory. The data sampling interval (D.I.) and spectral bandwidth (SBW) of every measurement were $0.7 \mathrm{~nm}$, to have good resolution, and the scan rate was relatively slow, $60 \mathrm{~nm} / \mathrm{min}$, to obtain a good signal/noise ratio. For the different pearl sizes, different black mat supports were used. Sample holders had different hole sizes (with a diameter from 2 to $10 \mathrm{~mm}$ ), to position the samples with the maximum possible exposed surface to measure, producing a more intense signal. For pearls with inhomogeneous color distribution (see Table 1), spectra were taken in differently colored areas. Before each measurement, background spectra were taken using a white $\mathrm{MgO}$ powder (for $100 \%$ ) and a black mat card (for $0 \%$ ) reference. All measurements were repeated at least twice, in order to confirm the repeatability of the results. Each measurement took about $25 \mathrm{~min}$.

The acquisition conditions for Raman scattering spectra are almost identical to those described previously in detail (Karampelas et al., 2007; see also Table 2). The main changes are the following:

(1) The acquisition time is increased from 20 to $60 \mathrm{~s}$ in order to improve the signal to noise ratio. This better reveals some weak components of the Raman bands, otherwise lost in noise.
Table 2. Excitation conditions, resolution and acquisition times for Raman measurements.

\begin{tabular}{lrccc}
\hline $\begin{array}{l}\text { Excitation } \\
\text { wavelength } \\
(\mathrm{nm})\end{array}$ & $\begin{array}{c}\text { Power } \\
\text { on the } \\
\text { sample } \\
(\mathrm{mW})\end{array}$ & $\begin{array}{c}\text { Acquisition } \\
\text { time (s) }\end{array}$ & Laser & $\begin{array}{c}\text { Resolution } \\
\left(\mathrm{cm}^{-1}\right)\end{array}$ \\
\hline 364 & 10 & 1200 & $\mathrm{Ar}^{+}$ & 6 \\
458 & 2 & 60 & $\mathrm{Ar}^{+}$ & 1.5 \\
488 & 2 & 60 & $\mathrm{Ar}^{+}$ & 1.5 \\
514 & 2 & 60 & $\mathrm{Ar}^{+}$ & 1 \\
561 & 1 & 60 & solid $^{+}$ & 0.8 \\
647 & 3 & 60 & $\mathrm{Kr}^{+}$ & 2.5 \\
1064 & 100 & 2000 & $\mathrm{Nd}$ :YAG & 4 \\
\hline
\end{tabular}

(2) We obtained measurements with yellow excitation using a semiconductor laser that emits at $561 \mathrm{~nm}$ with $10^{-5} \mathrm{~nm}$ spectral bandwidth, the backscattered light being then dispersed on a 1800 grooves $/ \mathrm{mm}$ holographic grating. This confirms the presence of certain pigments, harder to detect with only red and green excitation, and helps to demonstrate that they absorb (i.e., are Raman resonant) in this spectral region.

Raman spectra were all taken in the same area of the same sample by simply changing the excitation wavelength. This experimental area was always in the area where the UV-Vis-NIR diffuse reflectance spectrum was taken. All measurements were repeated at least twice, in order to ensure reproducibility. Note that the Raman spectra are normalized to the major Raman peak of aragonite (at $1085 \mathrm{~cm}^{-1}$ ), which is by far the major constituent of this kind of pearls. It can therefore be considered an internal standard. This allows a better comparison concerning relative intensity of the pigments signals. All spectra are vertically offset for clarity in the figures.

Overlapping Raman peaks at about $1500 \mathrm{~cm}^{-1}$ were decomposed for a finer analysis using Peak Fit 4.11 (Systat Software, Richmond, California). All bands were considered to have Gaussian shape. Band position (with an accuracy of $2 \mathrm{~cm}^{-1}$ ) and full width at half maximum (FWHM) were constrained for a given peak, so that only the intensity could be adjusted. In contrast to previous work (Karampelas et al., 2007), the FWHM used for the bands, whatever the excitation, was fixed at $10 \mathrm{~cm}^{-1}$.

\section{Results}

Compared to our previous study (Karampelas et al., 2007) we have added 5 samples from $H$. schlegeli (so-called Biwa cultured pearls) which show similar results (see Table 3). Moreover, with the new excitation used (at 561 $\mathrm{nm})$ often a new pigment is observed in some samples (e.g., at $1486 \mathrm{~cm}^{-1}$ for sample SK92, see again Table 3 ). The measurements of the samples common to our two 
Table 3. Absorptions observed in the visible spectral region (after visual decomposition; see text) as well as Raman bands observed using different excitation wavelengths (after decomposition with Peak Fit and constraints; see text) and estimated pigment composition (after Schaffer et al., 1991 and Barnard \& De Waal, 2006; Table 4). When the color is inhomogeneous, we report data for several measurement points. In bold are the peaks with the highest relative intensity (-: no other peaks than those of aragonite are observed).

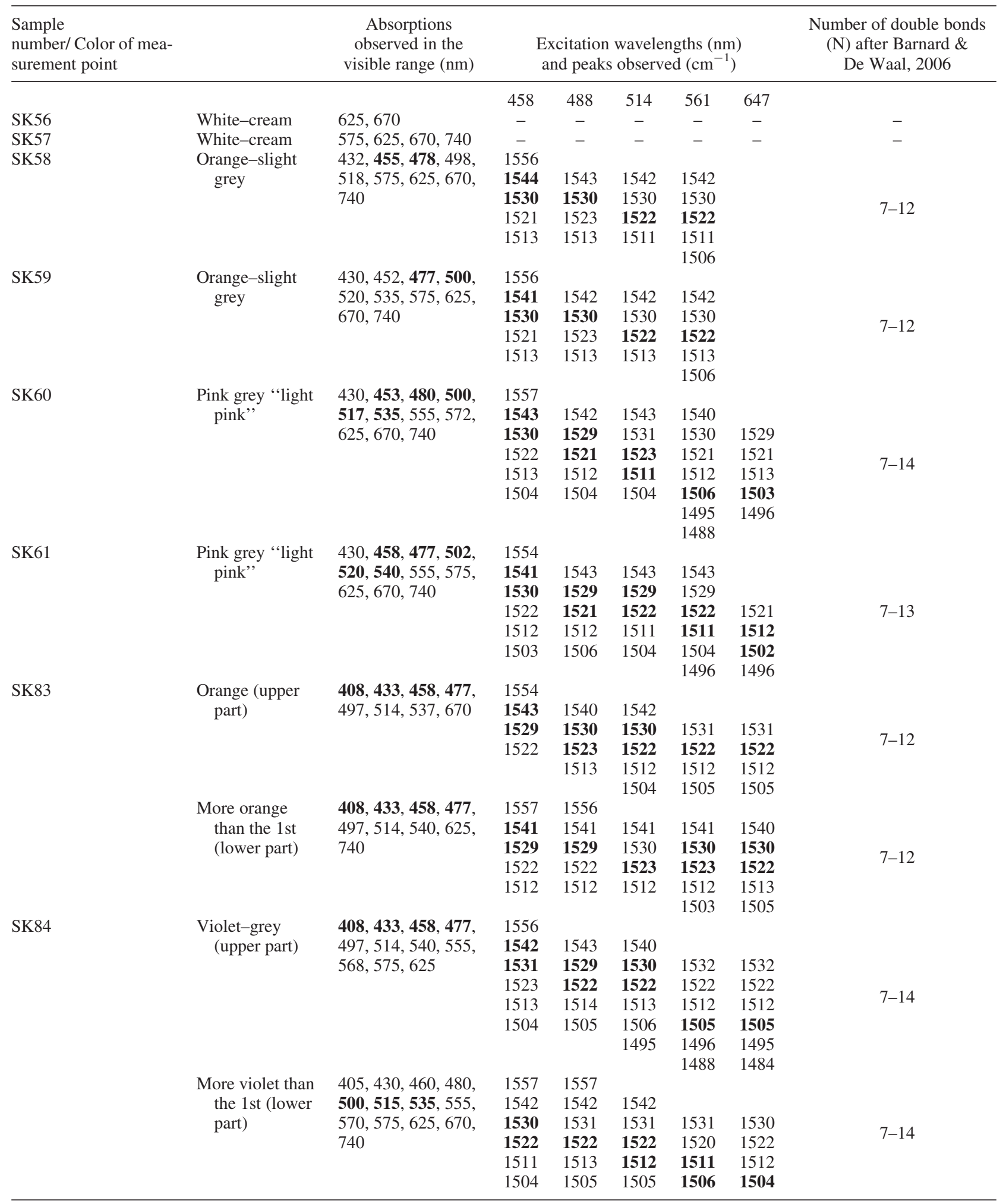


Table 3. Continued

\begin{tabular}{|c|c|c|c|c|c|c|c|c|}
\hline \multirow[t]{3}{*}{$\begin{array}{l}\text { Sample } \\
\text { number/ Color of mea- } \\
\text { surement point }\end{array}$} & & \multirow[t]{3}{*}{$\begin{array}{c}\text { Absorptions } \\
\text { observed in the } \\
\text { visible range (nm) }\end{array}$} & \multicolumn{5}{|c|}{$\begin{array}{l}\text { Excitation wavelengths }(\mathrm{nm}) \\
\text { and peaks observed }\left(\mathrm{cm}^{-1}\right)\end{array}$} & \multirow[t]{3}{*}{$\begin{array}{l}\text { Number of double bonds } \\
\text { (N) after Barnard \& } \\
\text { De Waal, } 2006\end{array}$} \\
\hline & & & & 1496 & 1496 & 1496 & 1496 & \\
\hline & & & & & & 1488 & 1487 & \\
\hline \multirow{15}{*}{ SK85 } & $\begin{array}{l}\text { Grey-little } \\
\text { violet (upper }\end{array}$ & $\begin{array}{l}405,435, \mathbf{4 5 6}, \mathbf{4 7 8}, \\
\mathbf{4 9 5} \mathbf{5 1 8}\end{array}$ & $\begin{array}{l}1554 \\
1541\end{array}$ & 1543 & 1542 & & & \\
\hline & part) & $570,575,625,670$ & 1530 & 1530 & 1530 & 1531 & 1530 & \\
\hline & & & 1521 & 1523 & 1521 & 1520 & 1520 & \\
\hline & & & 1511 & 1511 & 1513 & 1511 & 1510 & $7-14$ \\
\hline & & & & 1504 & 1505 & 1506 & 1504 & \\
\hline & & & & & & 1497 & 1497 & \\
\hline & & & & & & 1488 & & \\
\hline & More grey than & $405,432,455, \mathbf{4 8 0}$ & 1557 & 1555 & 1556 & & & \\
\hline & the 1st (lower & $\mathbf{4 9 8}, \mathbf{5 1 8}, \mathbf{5 3 7}, 555$ & 1543 & 1541 & 1542 & 1542 & & \\
\hline & part) & $570,575,625,670$ & 1529 & 1529 & 1531 & 1531 & & \\
\hline & & 740 & 1521 & 1521 & 1522 & 1521 & 1520 & \\
\hline & & & 1511 & 1510 & 1512 & 1511 & 1510 & $7-14$ \\
\hline & & & 1504 & 1503 & 1503 & 1503 & 1504 & \\
\hline & & & & & 1494 & 1494 & 1497 & \\
\hline & & & & & & 1484 & 1487 & \\
\hline \multirow[t]{15}{*}{ SK86 } & Pink-grey & $405, \mathbf{4 3 2}, \mathbf{4 5 7}, \mathbf{4 7 7}$ & 1556 & 1553 & & & & \\
\hline & "light pink" & $498,518,535,670$ & 1542 & 1541 & 1541 & 1540 & 1540 & \\
\hline & (upper part) & & 1529 & 1529 & 1529 & 1529 & 1529 & $7-12$ \\
\hline & & & 1522 & 1522 & 1521 & 1521 & 1521 & $1-12$ \\
\hline & & & 1511 & 1512 & 1512 & 1512 & 1511 & \\
\hline & & & & & 1504 & 1504 & 1505 & \\
\hline & More pink than & $405,435, \mathbf{4 5 8}, \mathbf{4 7 7}$ & 1568 & & & & & \\
\hline & the 1st (lower & $498,518,535,555$ & 1556 & 1556 & 1556 & 1556 & & \\
\hline & part) & $570,575,625$ & 1541 & 1542 & 1541 & 1541 & 1541 & \\
\hline & & & 1529 & 1529 & 1529 & 1529 & 1531 & \\
\hline & & & 1522 & 1522 & 1522 & 1522 & 1522 & $6-14$ \\
\hline & & & 1511 & 1512 & 1512 & 1512 & 1512 & \\
\hline & & & 1502 & 1503 & 1504 & 1504 & 1503 & \\
\hline & & & & & 1494 & 1494 & 1494 & \\
\hline & & & & & & 1486 & 1484 & \\
\hline \multirow{17}{*}{ SK87 } & Violet-grey & $405,434, \mathbf{4 5 5}, \mathbf{4 7 7}$ & 1569 & & & & & \\
\hline & (upper part) & $498,517,535,553$ & 1556 & & & & & \\
\hline & & $568,595,625$ & 1542 & 1543 & 1541 & 1541 & & \\
\hline & & & 1530 & 1530 & 1529 & 1529 & 1530 & \\
\hline & & & 1522 & 1522 & 1522 & 1522 & 1520 & $6-14$ \\
\hline & & & 1511 & 1511 & 1512 & 1512 & 1510 & \\
\hline & & & 1502 & 1502 & 1504 & 1504 & 1504 & \\
\hline & & & & & 1495 & 1495 & 1496 & \\
\hline & & & & & & 1485 & & \\
\hline & More violet than & $405, \mathbf{4 3 5}, \mathbf{4 5 5}, 478$ & 1568 & & & & & \\
\hline & the 1st (lower & $498,518,575,595$ & 1556 & 1557 & & & & \\
\hline & part) & 625 & 1542 & 1542 & 1542 & 1541 & & \\
\hline & & & 1529 & 1529 & 1530 & 1530 & 1529 & $6-13$ \\
\hline & & & 1522 & 1522 & 1522 & 1521 & 1521 & $0-13$ \\
\hline & & & 1512 & 1512 & 1513 & 1513 & 1512 & \\
\hline & & & 1504 & 1502 & 1504 & 1504 & 1505 & \\
\hline & & & & & & 1494 & 1496 & \\
\hline \multirow[t]{11}{*}{ SK88 } & Violet-grey & $405, \mathbf{4 3 5}, \mathbf{4 5 5}, 478$ & 1556 & 1555 & & & & \\
\hline & (upper part) & $498,518,538,555$ & 1541 & 1542 & 1541 & 1541 & & \\
\hline & & $570,595,625,670$ & 1529 & 1529 & 1529 & 1530 & 1530 & \\
\hline & & & 1522 & 1522 & 1522 & 1521 & 1520 & \\
\hline & & & 1511 & 1513 & 1511 & 1512 & 1511 & $7-14$ \\
\hline & & & 1504 & 1505 & 1503 & 1505 & 1505 & \\
\hline & & & & & & 1494 & 1497 & \\
\hline & & & & & & 1486 & 1486 & \\
\hline & More violet than & $408, \mathbf{4 3 0}, \mathbf{4 5 5}, 477$ & 1568 & & & & & $6-14$ \\
\hline & the 1st (lower & $498,518,540,558$ & 1557 & 1556 & & & & \\
\hline & part) & $570,595,625,670$ & 1541 & 1544 & 1542 & 1541 & & \\
\hline
\end{tabular}


Table 3. Continued

\begin{tabular}{|c|c|c|c|c|c|c|c|c|}
\hline \multirow[t]{7}{*}{$\begin{array}{l}\text { Sample } \\
\text { number/ Color of mea- } \\
\text { surement point }\end{array}$} & & \multirow[t]{7}{*}{$\begin{array}{c}\text { Absorptions } \\
\text { observed in the } \\
\text { visible range }(\mathrm{nm})\end{array}$} & \multicolumn{5}{|c|}{$\begin{array}{l}\text { Excitation wavelengths }(\mathrm{nm}) \\
\text { and peaks observed }\left(\mathrm{cm}^{-1}\right)\end{array}$} & \multirow[t]{7}{*}{$\begin{array}{l}\text { Number of double bonds } \\
\text { (N) after Barnard \& } \\
\text { De Waal, } 2006\end{array}$} \\
\hline & & & 1530 & 1530 & 1530 & 1530 & 1531 & \\
\hline & & & 1523 & 1522 & 1522 & 1522 & 1522 & \\
\hline & & & 1513 & 1512 & 1511 & 1511 & 1513 & \\
\hline & & & 1504 & 1504 & 1503 & 1503 & 1504 & \\
\hline & & & & & 1494 & 1492 & 1495 & \\
\hline & & & & & & & 1484 & \\
\hline \multirow[t]{8}{*}{ SK89 } & Violet-grey & $408,430,455,477$ & 1569 & & & & & \multirow{8}{*}{$6-13$} \\
\hline & & $\mathbf{4 9 8}, \mathbf{5 1 8}, \mathbf{5 4 0}, 555$ & 1555 & 1555 & 1555 & & & \\
\hline & & $570,595,625,670$ & 1542 & 1541 & 1540 & 1541 & & \\
\hline & & & 1530 & 1529 & 1529 & 1529 & 1532 & \\
\hline & & & 1521 & 1521 & 1521 & 1521 & 1523 & \\
\hline & & & 1512 & 1512 & 1511 & 1511 & 1513 & \\
\hline & & & 1503 & 1503 & 1504 & 1504 & 1504 & \\
\hline & & & & & 1495 & 1495 & 1495 & \\
\hline \multirow[t]{9}{*}{ SK90 } & Violet-grey & $405,430,455, \mathbf{4 8 0}$ & 1569 & 1568 & 1569 & & & \multirow{9}{*}{$6-14$} \\
\hline & & $\mathbf{4 9 8}, \mathbf{5 1 6}, 540,555$ & 1554 & 1555 & 1556 & 1554 & & \\
\hline & & $570,595,625,670$ & 1542 & 1541 & 1541 & 1540 & & \\
\hline & & 740 & 1531 & 1530 & 1530 & 1531 & 1530 & \\
\hline & & & 1523 & 1522 & 1523 & 1522 & 1522 & \\
\hline & & & 1511 & 1511 & 1512 & 1511 & 1513 & \\
\hline & & & 1503 & 1503 & 1503 & 1502 & 1505 & \\
\hline & & & 1495 & 1495 & 1495 & 1495 & 1496 & \\
\hline & & & 1485 & 1487 & 1485 & 1485 & 1485 & \\
\hline \multirow[t]{9}{*}{ SK91 } & Grey & $407,430, \mathbf{4 5 7}, \mathbf{4 7 8}$ & 1567 & & & & & \multirow{9}{*}{$6-14$} \\
\hline & & $\mathbf{4 9 8}, \mathbf{5 1 7}, 540,558$ & 1555 & 1555 & & & & \\
\hline & & $570,595,625,670$ & 1542 & 1542 & 1541 & 1543 & & \\
\hline & & 740 & 1530 & 1529 & 1530 & 1530 & 1530 & \\
\hline & & & 1522 & 1521 & 1521 & 1522 & 1521 & \\
\hline & & & 1512 & 1512 & 1512 & 1510 & 1511 & \\
\hline & & & 1504 & 1502 & 1504 & 1505 & 1503 & \\
\hline & & & & & 1494 & 1496 & 1497 & \\
\hline & & & & & & 1487 & 1484 & \\
\hline \multirow[t]{9}{*}{ SK92 } & Grey & $405,432,459,477$ & 1569 & & & & & \multirow{9}{*}{$6-14$} \\
\hline & & $\mathbf{4 9 8}, \mathbf{5 1 7}, 542,555$ & 1555 & 1557 & 1556 & & & \\
\hline & & $570,595,625,670$ & 1542 & 1543 & 1541 & 1543 & & \\
\hline & & 720,740 & 1530 & 1530 & 1529 & 1530 & 1530 & \\
\hline & & & 1523 & 1522 & 1522 & 1521 & 1521 & \\
\hline & & & 1512 & 1510 & 1512 & 1511 & 1512 & \\
\hline & & & 1503 & 1504 & 1503 & 1505 & 1504 & \\
\hline & & & & 1496 & 1494 & 1494 & 1494 & \\
\hline & & & & & & 1486 & 1485 & \\
\hline \multirow{7}{*}{ SK116 } & Slight yellow & $408, \mathbf{4 3 4}, \mathbf{4 5 3}, 478$ & 1555 & & & & & \multirow{7}{*}{$7-13$} \\
\hline & & $497,517,542,555$ & 1542 & 1543 & & 1542 & & \\
\hline & & $575,595,625,670$ & 1531 & 1531 & 1542 & 1530 & & \\
\hline & & 740 & 1522 & 1522 & 1530 & 1521 & & \\
\hline & & & 1510 & 1511 & 1522 & 1511 & & \\
\hline & & & & & 1510 & 1502 & & \\
\hline & & & & & & 1496 & & \\
\hline SK117 & Slight purple- & $455,478,498,517$ & 1542 & 1542 & & & & \\
\hline & grey "light & $542, \mathbf{5 5 5}, \mathbf{5 7 2}, 595$ & 1531 & 1531 & 1530 & 1530 & & \\
\hline & purple"" & $625,670,695$ & 1521 & 1522 & 1521 & 1520 & & 812 \\
\hline & & & 1511 & 1511 & 1511 & 1511 & & $8-13$ \\
\hline & & & 1505 & 1504 & 1504 & 1504 & & \\
\hline & & & & & & 1496 & & \\
\hline SK118 & Pink-grey & $432,455,478,498$ & 1555 & & & & & \\
\hline & "light pink" & $517, \mathbf{5 4 1}, \mathbf{5 5 5}, 572$ & 1542 & 1543 & 1543 & 1543 & & \\
\hline & & $595,625,670,720$ & 1531 & 1531 & 1531 & 1531 & & \\
\hline & & & 1520 & 1520 & 1521 & 1520 & & $7-13$ \\
\hline & & & 1511 & 1511 & 1511 & 1512 & & \\
\hline & & & 1504 & 1504 & 1501 & 1502 & & \\
\hline & & & & & 1497 & 1497 & & \\
\hline
\end{tabular}


Table 3. Continued

\begin{tabular}{|c|c|c|c|c|c|c|c|}
\hline $\begin{array}{l}\text { Sample } \\
\text { number/ Color of mea- } \\
\text { surement point }\end{array}$ & & $\begin{array}{c}\text { Absorptions } \\
\text { observed in the } \\
\text { visible range (nm) }\end{array}$ & \multicolumn{4}{|c|}{$\begin{array}{l}\text { Excitation wavelengths }(\mathrm{nm}) \\
\text { and peaks observed }\left(\mathrm{cm}^{-1}\right)\end{array}$} & $\begin{array}{l}\text { Number of double bonds } \\
\text { (N) after Barnard \& } \\
\text { De Waal, } 2006\end{array}$ \\
\hline SK119 & $\begin{array}{l}\text { Pink-grey } \\
\text { "light pink" }\end{array}$ & $\begin{array}{l}435,455,478,498, \\
518, \mathbf{5 4 2}, \mathbf{5 5 5}, 572, \\
595,625,670,720\end{array}$ & $\begin{array}{l}1556 \\
1543 \\
\mathbf{1 5 3 1} \\
\mathbf{1 5 2 2} \\
1511\end{array}$ & $\begin{array}{l}1556 \\
1543 \\
\mathbf{1 5 3 1} \\
\mathbf{1 5 2 1} \\
1511\end{array}$ & $\begin{array}{l}1543 \\
1530 \\
\mathbf{1 5 2 1} \\
\mathbf{1 5 1 1} \\
1503\end{array}$ & $\begin{array}{l}1531 \\
\mathbf{1 5 2 1} \\
\mathbf{1 5 1 1} \\
1502 \\
1497\end{array}$ & $7-13$ \\
\hline SK120 & $\begin{array}{l}\text { White (very } \\
\text { light grey) }\end{array}$ & $\begin{array}{l}435,458,477,497 \\
518,542,555,572, \\
575,595,625,670, \\
695,720\end{array}$ & $\begin{array}{l}1555 \\
\mathbf{1 5 4 1} \\
\mathbf{1 5 3 0} \\
1521 \\
1512\end{array}$ & $\begin{array}{l}1542 \\
\mathbf{1 5 3 1} \\
\mathbf{1 5 2 1} \\
1511\end{array}$ & $\begin{array}{l}1542 \\
\mathbf{1 5 3 1} \\
\mathbf{1 5 2 1} \\
1511\end{array}$ & & $7-11$ \\
\hline
\end{tabular}

investigations are updated from this previous study, taking into account slight differences in method. There are actually very few differences (see also Table 3 ), so details are not repeated here and can be found in the previous publication.

The main points are that, in the spectra of the white cultured freshwater pearls, we observe a band at about $1085 \mathrm{~cm}^{-1}$ and a doublet at about 702 and $706 \mathrm{~cm}^{-1}$ (Fig. 1) which correspond respectively to the $v_{1}$ symmetric stretching and the $v_{4}$ in-plane bending modes of the carbonate ion $\left(\mathrm{CO}_{3}^{2-}\right)$ in aragonite (Urmos et al., 1991). Moreover, all colored samples present two intense additional bands in the $1000-1600 \mathrm{~cm}^{-1}$ region (e.g., Fig. 2). These are characteristic of polyenic chains (Salares et al., 1977). Some slight changes in shape and relative intensities of the two more intense bands are visible from one sample to the next. Such changes occur for the same area of

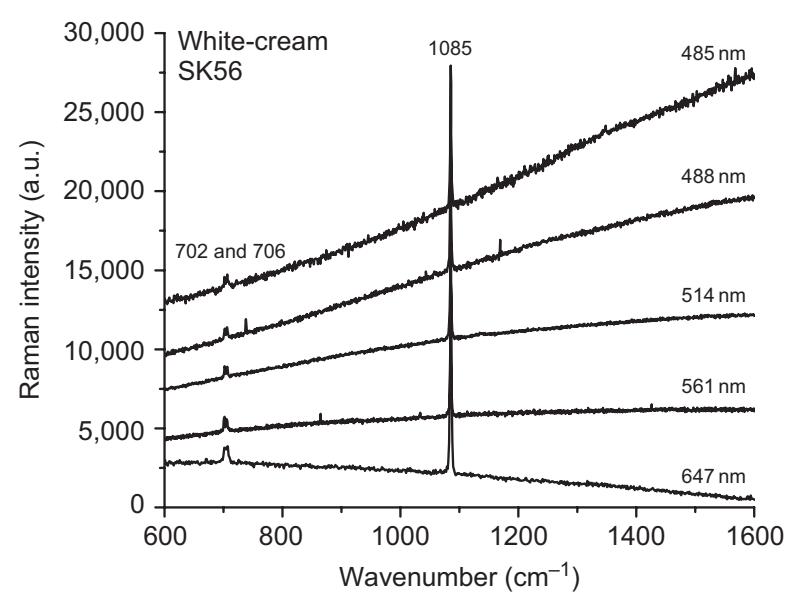

Fig. 1. Raman spectra of a white-cream pearl (SK56; diffuse reflectance spectrum is presented in Fig. 3), using five different excitation wavelengths. Only Raman peaks due to aragonite are present, at $1085 \mathrm{~cm}^{-1}\left(v_{1}\right.$ symmetric stretching mode of carbonate), and a doublet at about $702-706 \mathrm{~cm}^{-1}$ ( $v_{4}$ in-plane bending of carbonate). the same sample by simply changing the excitation wavelength (see Fig. 2 and Table 3). The main changes are observed at about $1500 \mathrm{~cm}^{-1}$ (approximate position of the peak corresponding to the double carbon-carbon stretching vibration, $v_{1}$ ). This is a very "sensitive" region to the length of the polyenic chain (Schügerl \& Kuzmany, 1981; Schaffer et al., 1991; Barnard \& De Waal, 2006). Positions of the band at about $1500 \mathrm{~cm}^{-1}$ are summarized in Table 4 as a function of the effective number of carbon double bonds in the polyenic chain, using equations previously established (Schaffer et al., 1991; Barnard \& De Waal, 2006) slightly extrapolated for the range $N=12$ to 14 (Karampelas et al., 2007). After decomposition of the spectra, it is estimated that up to 9 different bands may be found in the same pearl, at about 1486, 1495, 1504, 1512, 1521, 1531, 1542, 1555 and $1569 \mathrm{~cm}^{-1}$ (positions $\pm 2 \mathrm{~cm}^{-1}$ ) (Table 3). Each pearl is colored by a mixture of unsubstituted polyenes, with a general formula R-(-CH=CH- ${ }_{N}-\mathrm{R}^{\prime}$, with $N=6$ to 14 . All our colored samples contained at least five pigments $(N=7-11)$ and up to nine. Shorter excitation wavelengths excite pigments with Raman peaks at higher wavenumber position (Table 3 ). Unmethylated polyenes which absorb in the ultraviolet (with $N<6$ ) may also be present in these pearls.

The $v_{2}$ bands are dependent upon inverse conjugation or chain length of polyene chains too (Schaffer et al., 1991; Table 4). In our samples, the position of the single carboncarbon stretching vibration $\left(v_{2}\right)$ is shifted as well as a function of sample color and excitation wavelength, with apparent maxima in the range from about 1120 to 1140 $\mathrm{cm}^{-1}$, thus comprising component bands from about 1115 to $1160 \mathrm{~cm}^{-1}$. Moreover, weak bands related to polyenes are revealed in all our spectra (Fig. 2) at about 1010, 1190 and $1295 \mathrm{~cm}^{-1}$, but they are not useful to provide further details on the pigments. No changes in shape and full width at half maximum (FWHM: $2.1 \pm 0.1 \mathrm{~cm}^{-1}$ ) of the $v_{1}$ aragonite band are noted from one sample to the other. In addition, no peaks linked to other carbonate polymorphs (e.g., calcite and vaterite) were observed. 


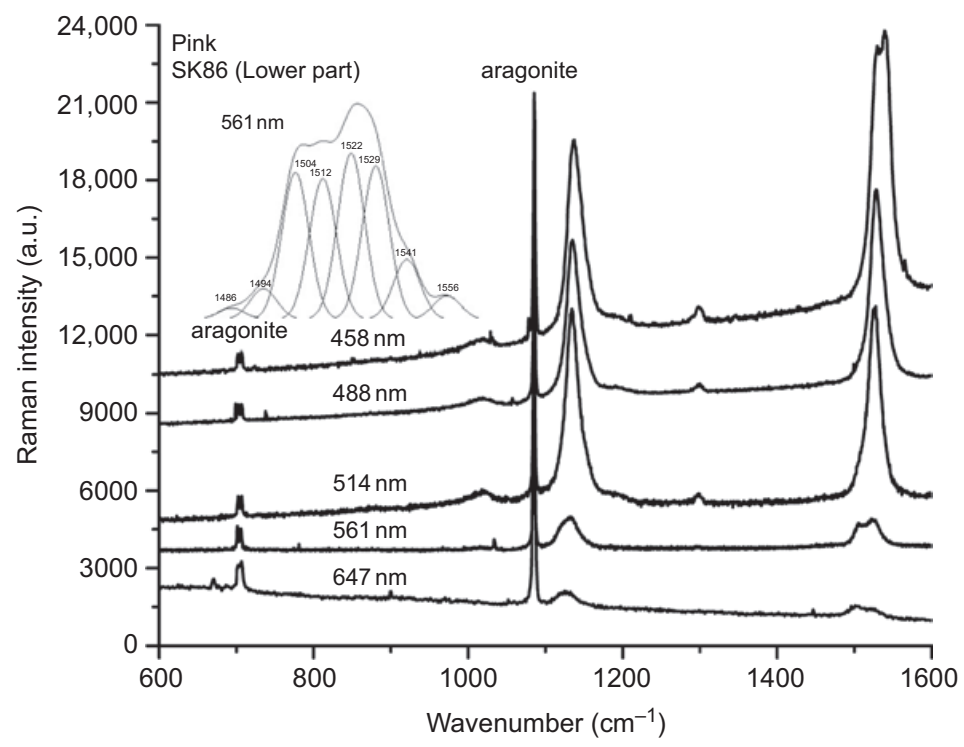

Fig. 2. Raman spectra of the lower part of a pink freshwater cultured pearl (SK86; diffuse reflectance spectrum is presented in Fig. 5) using five excitation wavelengths. The $v_{1}$ band decomposition (with Peak Fit and constraints; see text) for the spectrum obtained with excitation at $561 \mathrm{~nm}$ is shown as inset.

Table 4. Positions of $v_{1}$ and $v_{2}$ bands as a function of the number of carbon double-bonds in the polyenic chain (as calculated from Schaffer et al., 1991, and Barnard \& De Waal, 2006) as well as correlation of decomposed Raman peaks and visible absorption features of samples measured in this study.

\begin{tabular}{|c|c|c|c|c|c|}
\hline $\begin{array}{l}\text { Number of carbon } \\
\text { double bonds }(N)\end{array}$ & $\begin{array}{c}v_{2}\left(\mathrm{~cm}^{-1}\right) \\
\text { Schaffer et al., } \\
1991\end{array}$ & $\begin{array}{c}v_{1}\left(\mathrm{~cm}^{-1}\right) \\
\text { Schaffer et al., } \\
1991\end{array}$ & $\begin{array}{c}v_{1}\left(\mathrm{~cm}^{-1}\right) \\
\text { Barnard \& De Waal, } \\
2006\end{array}$ & $\begin{array}{c}v_{1}\left(\mathrm{~cm}^{-1}\right) \\
\text { Karampelas et al., } \\
2007 \text { and this study }\end{array}$ & $\begin{array}{l}\text { Absorption in the } \\
\text { visible (nm), this } \\
\text { study }\end{array}$ \\
\hline 3 & & & 1638.4 & & \\
\hline 4 & & & 1610.4 & & \\
\hline 5 & & & 1588.8 & 1587 & \\
\hline 6 & & & 1571.1 & 1569 & 405 \\
\hline 7 & & 1555.6 & 1556.1 & 1555 & 432 \\
\hline 8 & 1140.1 & 1542.2 & 1543.2 & 1542 & 455 \\
\hline 9 & 1134.9 & 1530.9 & 1531.7 & 1531 & 478 \\
\hline 10 & 1129.8 & 1520.9 & 1521.5 & 1521 & 498 \\
\hline 11 & 1125.1 & 1514.0 & 1512.2 & 1512 & 518 \\
\hline 12 & 1121.8 & 1505.9 & 1503.8 & 1504 & 535 \\
\hline 13 & & & & 1495 & 552 \\
\hline 14 & & & & 1486 & 568 \\
\hline
\end{tabular}

In Figs. 3-5 the UV-Vis-NIR diffuse reflectance spectra of different natural color cultured freshwater pearls in the 250-900 nm range are presented. All spectra revealed a decrease in diffuse reflectance due to absorption in the ultraviolet range at $280 \mathrm{~nm}$. This peak is found in all pearls examined for this study, regardless of their color. Figure 3 shows that all the light of the visible part of the spectrum $(390-780 \mathrm{~nm})$ is transmitted, in agreement with the white color. We observe also two small absorptions at 620 and $670 \mathrm{~nm}$.

Figure 4 shows the UV-Vis-NIR spectra of the upper parts of a natural orange (SK83 up) and a violet grey (SK87 up) cultured freshwater pearl. In both spectra we observe absorptions mainly in the blue and green range (450-540 nm). The pearl SK83 absorbs also the violet $(390-450 \mathrm{~nm})$ with a transmission window in the orange range. The pearl SK87 exhibits absorption at approximately the same level throughout the visible spectrum, thus the overall grey color, but additionally has small transmission windows in the yellow to red range, apparently responsible for the violet hue. Moreover, absorptions in the violet (390$450 \mathrm{~nm}$ ) are less intense compared to those in the blue and green part $(450-540 \mathrm{~nm})$, another factor which plays a role for the violet hue.

In Fig. 5, UV-Vis-NIR spectra of the natural color cultured freshwater pearl (SK86), of the upper (light 




Fig. 3. Diffuse reflectance spectrum in the $250-900 \mathrm{~nm}$ range of a white-cream cultured freshwater pearl (SK56). A decrease in reflectance due to absorption in the ultraviolet range at $280 \mathrm{~nm}$ is observed All wavelengths of the visible part of the spectrum $(390-780 \mathrm{~nm})$ are transmitted. Two weak absorptions at 620 and $670 \mathrm{~nm}$ are marked by arrows.



Fig. 4. Diffuse reflectance spectra in the $250-900 \mathrm{~nm}$ range of the upper part of a natural orange (SK83 up) and violet-grey (SK87 up) cultured freshwater pearl. In both spectra we observe that the most intense absorptions are in the violet, blue and green part of the spectrum (390-540 nm). However, the spectra are different in the visible region, as expected. The spectrum of SK87 up is shifted down by $5 \%$ for clarity.

pink; pinkish grey) and the lower part (pink) are given. As expected, the two spectra are different in the visible range (see again Fig. 5). In the upper part, weaker absorptions spread mostly over the violet and the blue range, whereas the lower part absorbs more strongly, even in the green part, giving the more saturated pink color.

It has been previously established from Raman spectroscopy that the color results from the presence of nine pigments at the most. The visible diffuse reflectance data have to be consistent with the Raman scattering ones.

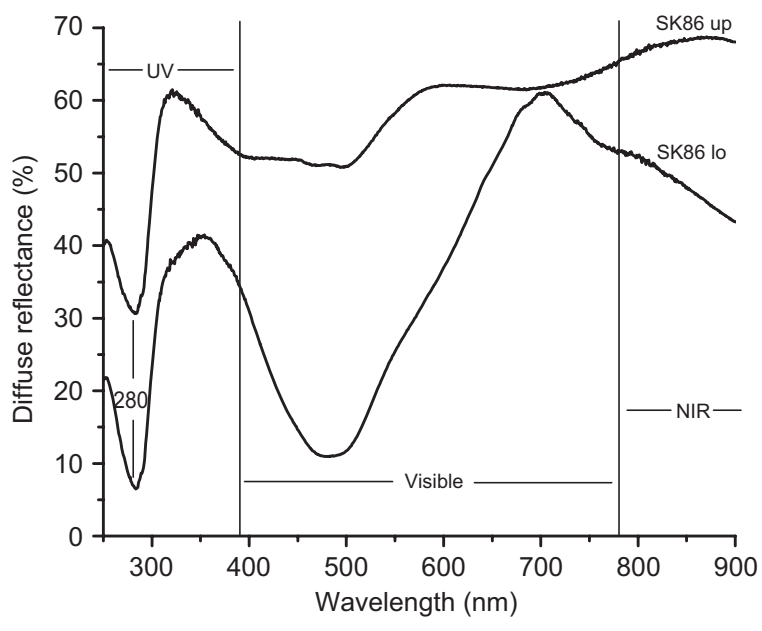

Fig. 5. Diffuse reflectance spectra in the $250-900 \mathrm{~nm}$ range of the upper and lower part of the cultured freshwater pearl SK86. The upper part is light pink (pinkish grey) and the lower part pink. The two spectra are different in the visible region. The spectrum of SK86 lo is shifted down by $20 \%$ for clarity.

Hence, according to a tentative simplified approach, there should be as many absorptions bands as there are pigments for any given pearl. Therefore, one would expect in a given sample the same number of components in the diffuse reflectance spectrum as the number of pigments previously established via Raman scattering. Some diffuse reflectance spectra appear relatively continuous and smooth, suggesting that they are composed of one single very wide Gaussian band (Fig. 6 bottom, SK87up). However, other

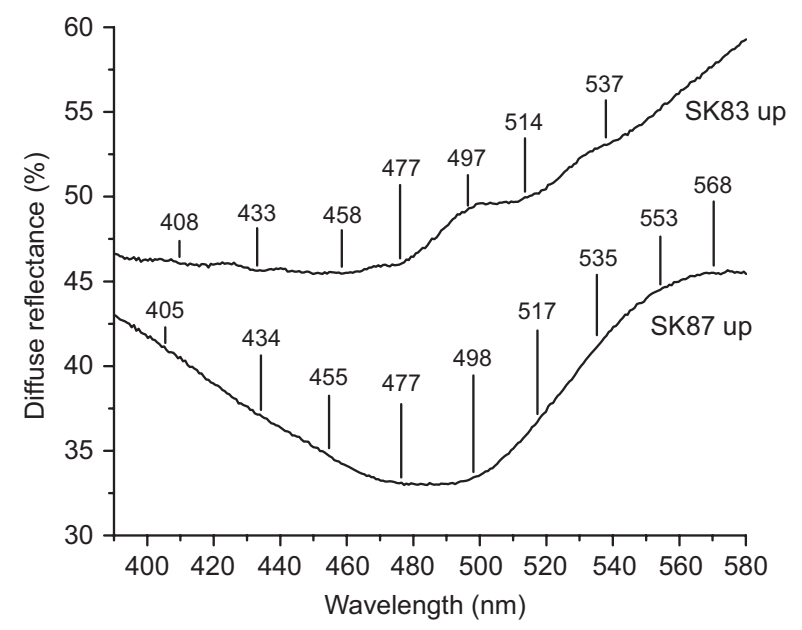

Fig. 6. Diffuse reflectance spectra in the $390-580 \mathrm{~nm}$ range for samples presented in Fig. 4 (SK83 up and SK 87 up). Bands observed (after visual decomposition; see text) at about $( \pm 5 \mathrm{~nm}) 405$ (408 for SK83 up), 432 (433 for SK83 up and 434 for SK87 up), 457 (458 for SK83 up and 455 for SK87 up), 477, 498 (497 for SK83 up), 516 (514 for SK83 up and 517 for SK87 up), 535 (537 for SK83 up), 552 (not observed for SK83 up and 553 for SK87 up) and 568 (not observed for SK83 up) nm. The spectrum of SK87 up is shifted down by $5 \%$ for clarity. 
spectra clearly show the presence of many components, as is particularly apparent in Fig. 6 top (SK83up). Those are used to visually estimate the apparent maxima of at least some of the components. Looking at all the diffuse reflectance spectra, a list of all the maxima (i.e., components) observed is established. Nine major ones are observed, as well as a series of weaker absorptions that may not play a significant role in the color. Hence, the spectra in Fig. 6 result from linear combinations of Gaussian bands with maxima at about $( \pm 5 \mathrm{~nm}): 405,432,457,477,498,516$, 535,552 and $568 \mathrm{~nm}$ (see also Table 3). In other words, to compose the absorption pattern, one needs a combination of these elementary bands.

Absorptions, always weaker than those cited above, are revealed in some spectra from yellow to red at about 575 , 595, 625 (e.g., SK87 up; Fig. 4), 670 (e.g., SK83 up; Fig. 4), 695, 720 and $740 \mathrm{~nm}$ (see Table 3). Some samples exhibit absorptions features also in the ultraviolet at about 320, 345 and $370 \mathrm{~nm}$ (e.g., SK87 up; Fig. 4 and SK 86 up and lo; Fig. 5). Other bands are observed in the near-infrared region. Because of their position or weak intensity, these bands do not play a role in the color of the samples.

\section{Discussion}

The major absorption features for all the natural color samples studied are found from violet to green-yellow, from 390 to $570 \mathrm{~nm}$. Moreover, the two Raman resonance features of polyenes, assigned to the $C=C\left(v_{1}\right.$ near 1500 $\left.\mathrm{cm}^{-1}\right)$ and $\mathrm{C}-\mathrm{C}$ stretching vibrations $\left(v_{2}\right.$ near $\left.1130 \mathrm{~cm}^{-1}\right)$, are observed. These Raman bands can be assigned to a series of unsubstituted (unmethylated) polyenes (Okamoto et al., 1984; Merlin \& Delé-Dubois, 1986; Veronelli et al., 1995; Barnard \& De Waal, 2006; Hedegaard et al., 2006; Karampelas et al., 2006 and 2007).

The fact that these Raman bands are observed in naturally colored cultured freshwater pearls and not in white ones suggests that these compounds play the main role for the color of these samples. If we assume that the polyenic chains contained in pearl pigments are free of any perturbation, then it appears after spectral decomposition that a cultured freshwater pearl may contain different pigments which have 6 to 14 double bonds in their polyenic chains (see Tables 3 and 4). The nature of the terminal groups cannot be determined from our spectra. As these terminal groups are not associated with the resonance phenomenon, the respective bands are certainly too weak to be observed (Merlin \& Delé-Dubois, 1986). Thus, we can only determine a general formula for the pigments present in cultured freshwater pearls as $\mathrm{R}-(-\mathrm{CH}=\mathrm{CH}-)_{N}-\mathrm{R}^{\prime}$ with $N=6$ to 14 . Unmethylated polyenes which absorb in the ultraviolet (with $N<6$ ) may also be present in these pearls. However, it is difficult to detect them because of experimental difficulties (the microscope coupled to the Raman spectrometer is very poorly transparent to UV light). These bands would not play a role in the coloration of the pearls anyway.
A relation between the positions of the Raman peaks and the absorption features can be established. The absorption maximum for the lowest energy optical transition of molecules containing a polyenic chain has a linear dependence with inverse conjugation (Schaffer et al., 1991). Longer polyenic chains give absorption maxima at lower energies (higher wavelengths). Thus, tuning the laser for excitation wavelength selects conjugated chains of a specific range of conjugation length. The fact that in our samples different peak intensities are obtained for different excitation wavelengths proves that each pigment has a different absorption spectrum in the visible part of the spectrum. For shorter excitation wavelengths Raman resonant spectra reveal Raman bands having higher Raman shifts (thus, shorter chain length). This is in agreement with observations in Table 3 and Fig. 2. Peaks with lower and higher Raman shifts are due to respectively longer or shorter chain lengths, pigments with 13 and 14 double bonds (peaks at about 1495 and $1486 \mathrm{~cm}^{-1}$ respectively) are revealed clearly with yellow excitation (561 $\mathrm{nm}$ ). With red excitation the same bands are also revealed with lower intensity. Thus, no additional bands are observed in the orange and the red spectral range due to polyenes. Pigments with less than 9 double bonds are best excited at $458 \mathrm{~nm}$. This is in agreement with previous publications, which also stated that longer polyenic chains have a lower Raman shifts and visible absorption at shorter wavelengths (Salares et al., 1977; Schaffer et al., 1991).

The pigments with $v_{1}$ peaks below $1504 \mathrm{~cm}^{-1}$ have polyenic chains with $N>12$. These peaks are absent (or barely seen) for pearls with pink, orange and yellow colors (e.g., Table 3 and Fig. 2 with excitation at 561 and 647 $\mathrm{nm})$. Thus, pigments with $6 \leq N \leq 11$ absorb from the yellow to the violet part of the visible range. Hence they induce pink (absorption typically around the yellowgreen), orange (absorption typically from the violet to blue) and yellow colors when they are relatively concentrated. In colored samples the main absorptions are observed from violet to yellow-green (405 to $568 \mathrm{~nm}$ ). Absorption at lower energy (568 nm) seems to correspond to the Raman peak at $1486 \mathrm{~cm}^{-1}$. In the same way, absorption at higher energy in the visible range $(405 \mathrm{~nm})$ is linked with the peak at $1569 \mathrm{~cm}^{-1}$. This first approach of the relation between absorption features in the visible range and Raman peaks is summarized in Table 4. Absorptions with $N=9-11$ are the most common.

Pigments which absorb from yellow-orange to red (575, 595, 625, 670, 695, 720 and $740 \mathrm{~nm}$ ) do not present Raman resonance as those absorbing from violet to yellow-green, thus they are not polyenes. In the diffuse reflectance spectra, the absorptions cited above are not more intense than those due to polyenes. These absorptions are probably linked with undetermined impurities that may be contained in pearls or with other organic molecules that do not give measurable Raman peaks. Further research is needed in order to establish the origin of these minor absorptions. Absorption features in the UV region (at about 320,345 and $370 \mathrm{~nm}$ ) may be observed in cultured freshwater pearls. It is likely that these peaks are caused by 
polyenes with $N<6$ (Raman shifts above $1569 \mathrm{~cm}^{-1}$; see Table 4).

The nature and relative proportions of the pigments listed in Table 4 define a pearl's color. Thus, different mixtures of purple, orange and pink are due to different mixtures of pigments in varying relative proportions. However, similar colors can be caused by different mixtures of pigments (e.g., SK89 and SK90). Moreover, grey colors are due to mixtures of pigments absorbing in the visible range with similar efficiency. Also a light color is due to a slightly dominating absorption by the group of pigments giving this specific color. Because of the sensitivity of resonant Raman scattering, pigments can be detected at very low concentrations, that is, even when they do not play an appreciable role in color. Hence in some cases, Raman peaks due to pigments may be detected with low intensity in white or very light-colored pearls (e.g., Table 3; SK120).

In our spectra, $v_{2}$ bands are shifted for different pigments as well. However, the superposition of several bands is not as easily seen as for the $v_{1}$ band, and doublets are barely resolved. This is because the bands of the different polyenes are very close to one another, e.g. at about 1125 and $1122 \mathrm{~cm}^{-1}$ for polyenes containing respectively 11 and 12 double bonds. Moreover, $v_{2}$ bands above 1150 $\mathrm{cm}^{-1}$ may be observed too. These bands should not be linked to carotenoids (peaks at $>1150 \mathrm{~cm}^{-1}$ ), as stated by Soldati et al. (2008), but to unmethylated polyenes with very short polyenic chain $(\mathrm{N} \leq 6)$ (see also Table 4$)$.

In polyacetylenic molecules, weak bands are revealed in all of our Raman spectra at about 1010, 1190 and $1295 \mathrm{~cm}^{-1}$. The band at about $1295 \mathrm{~cm}^{-1}$ is assigned to the $\mathrm{CH}=\mathrm{CH}$ in-plane rocking mode $\left(v_{3}\right)$, whereas the band at about $1010 \mathrm{~cm}^{-1}$ is assigned to the deformation-activated $\mathrm{CH}=\mathrm{CH}$ wagging mode $\left(v_{4}\right)$, rather than the methyl rocking mode (Fujimori et al., 2004; Barnard \& De Waal, 2006). In some cases a weak band at about $1190 \mathrm{~cm}^{-1}$ is also found. Bands in this region are attributed to the $\mathrm{C}-\mathrm{C}$ stretching and the $\mathrm{C}-\mathrm{H}$ in-plane bending modes in $\beta$-carotene (Saito \& Tasumi, 1983). In our case, no methyl groups are attached to the polyenic chain, thus only the $\mathrm{C}-\mathrm{C}$ stretching seems to be responsible for this peak.

Variations in the positions and FWHM of Raman bands of carbonates may indicate rotational disordering of the carbonate ion in carbonates (Urmos et al., 1991). However, spectra of all measured samples do not show any change in position and FWHM of the major $\left(v_{1}\right)$ aragonite peak. This is probably because of the low degree of trace element substitution in aragonite $\left(<1 \%\right.$ for $\mathrm{Sr}^{2+}$; Urmos et al., 1991). The fact that no difference is observed in Raman bands of carbonates for white and colored samples is suggestive that a $\mathrm{CaCO}_{3}$-pigment complex is unlikely. Thus the most probable hypothesis is a complex with pearls' organic matrix. Pearls, similarly to the nacreous part of shells, do contain $\beta$-chitin as a major protein, as well as an assemblage of acidic glycoproteins (Levi-Kalisman et al., 2001). Thus, a complex with a part of these matrices is the most likely at this point.
Our preliminary results on pearls and/or shells from different genus (other than Hyriopsis) suggest that the same pigment may not necessarily exhibit exactly the same absorption in different genus. This is probably because polyenes are attached in different ways, thus they offer slightly different absorption features.

Unmethylated polyenes have rarely been observed in nature, as stated above. Determination of the exact chemical structure of these pigments has hitherto been hindered because their extraction is difficult and the isolated products are extremely unstable (Merlin \& Delé-Dubois, 1983; Veronelli et al., 1995; Stradi et al., 2001b). As a consequence, their synthesis process is still unknown. Recently, Stradi et al. (2001b) used advanced chemical methods (HPLC coupled with UV-Vis spectroscopy and mass spectrometry) on feathers of Ara Macao (a species of parrot) in order to find the exact chemical structure of the feather pigments. These authors proposed that it is actually a mixture of four pigments containing polyenic chains of general formula $\mathrm{CH}_{3}-(-\mathrm{CH}=\mathrm{CH}-)_{N}-\mathrm{CHO}$ with $N=6-9$. Recently, McGraw \& Nogare's (2004) results concerning parrots' coloration systems suggest that these pigments cannot originate from dietary sources (as is the case for carotenoids). They are locally synthesized, likely within the mantle tissue (in the follicular tissue of growing feathers). Thus, possibly there is, also, no direct link between pearl color and food. Moreover, the fact that different colors are observed at different points of the same pearl suggests that different series of pigments are secreted at the same time.

\section{Conclusions}

All naturally colored cultured freshwater pearls investigated in this study are colored by a mixture of unsubstituted polyenes. These pigments absorb from the violet to the yellow-green spectral range and appear to be the major cause of their color. Their general formula is $\mathrm{R}-(-\mathrm{CH}=\mathrm{CH}-)$ ${ }_{N}-\mathrm{R}^{\prime}$ with $N=6-14$. We have established a relation between $\mathrm{N}$ and the absorption maximum for each pigment in freshwater cultured pearls. Pigments with $N>14$ are absent in the samples studied. Molecules with $N<6$ may be observed in cultured freshwater pearls. However, they absorb in the ultraviolet, thus they do not play a role in the color. Other absorptions, always less intense compared to the polyene ones, are observed in the yellow-orange to red range. Extraction may shed further light on the origin of these absorptions. Understanding the nature of the pigments in natural-color freshwater pearls can help to separate them from their treated equivalents.

Similar series of pigments are found in pearls (either fresh- or salt-water) and/or their shells. Our preliminary results suggest that the same pigment does not cause the exact same absorption features in samples from different mollusk genus. A study of the precise relation between optical absorption, Raman peaks and mollusks' genus of the samples is ongoing. 
Thus, pigments contained in pearls are not carotenoids, they rather belong to the same unique class of biochromes named psittacofulvins as the lipid-soluble pigments in the parrots' feather. The identification of the exact chemical formula of these pigments would be useful, even though experimentally challenging. This would provide a better understanding of the biosynthesis of unsubstituted (unmethylated) polyenes coloring naturally the cultured freshwater pearls as well as other mollusks.

Acknowledgements: We wish to thank Mr. Alain Boite, Alain Boite Co., Paris, France, for loaning more than half the pearls studied. Other samples were obtained from Professor J.-P. Gauthier, from Lyon University, France and from LFG (Laboratoire Français de Gemmologie), Paris, France. SK is grateful to the Hellenic General Secretariat for Research and Technology (G.S.R.T.) for financial assistance (PENED 2003) during this project. The Programme PENED is implemented in the context of Measure 8.3 of the Operational Programme "Competitiveness" and is co-financed by the European Social Fund $(75 \%)$ and by national sources $(25 \%)$. We wish also to thank Dr. Claus Hedegaard, one anonymous reviewer as well as Dr. Eugen Libowitzky and Dr. Manfred Wildner (special editors of this volume) for their constructive reviews which helped to significantly improve the manuscript.

\section{References}

Barnard, W. \& De Waal, D. (2006): Raman investigation of pigmentary molecules in the molluscan biogenic matrix. J. Raman Spectrosc., 37, 342-352.

Ermakov, I.V., Ermakova, M.R., Gellermann, W. (2005): Simple Raman instrument for in vivo detection of macular pigments. Appl. Spectrosc., 59, 861-867.

Fengming, H., Xinqiang, Y., Mingxing, Y., Zhonghui, C. (2003): Pearl cultivation in Donggou, Ezhou, Hubei, and cathodoluminescence of cultured pearls. J. Gemmol., 28, 449-462.

Fox, D.L. \& Wilkie, D.W. (1970): Somatic and skeletally fixed carotenoids of the purple hydrocoral, Allopora californica. Comp. Biochem. Physiol., 36, 49-60.

Fujimori, K., Sakamoto, A., Tasumi, M. (2004): Relationship between the distortion of polyene chains from planarity and the Raman activity of the in-phase $\mathrm{CH}$ out-of-plane wag. Macromol. Symp., 205, 33-46.

Hänni, H.A. (1999): Sur la formation de nacre et de perles. Rev. Gemmol. A.F.G., 137, 30-36.

Hedegaard, C., Bardeau, J.-F., Chateigner, D. (2006): Molluscan shell pigments: an in situ resonance Raman study. J. Molluscan Stud., 72, 157-162.

Heller, C., Leising, G., Godon, C., Lefrant, S., Fischer, W., Stelzer, F. (1995): Raman excitation profiles of conjugated segments in solution. Phys. Rev. B, 51, 8107-8114.

Hoskins, C. \& Alexander, V. (1977): Determination of carotenoid concentrations in marine phytoplankton by resonance Raman spectrometry. Anal. Chem., 49, 695-697.
Karampelas, S., Fritsch, E., Sklavounos, S., Soldatos, T. (2006): Identification through Raman scattering of pigments in cultured freshwater pearls. Gems Gemol., 42, 99-100.

Karampelas, S., Fritsch, E., Mevellec, J.-Y., Gauthier, J.-P., Sklavounos, S., Soldatos, T. (2007): Determination by Raman scattering of the nature of pigments in cultured freshwater pearls from the mollusk Hyriopsis cumingi. J. Raman Spectrosc., $\mathbf{3 8}$, 217-230.

Levi-Kalisman, Y., Falini, G., Addadi, L., Weiner, S. (2001): Structure of the nacreous organic matrix of a bivalve mollusk shell examined in the hydrated state using cryo-TEM. J. Struct. Biol., 135, 8-17.

Li, L. \& Chen, Z. (2001): Cultured pearls and colour-changed cultured pearls: Raman spectra. J. Gemmol., 27, 449-455.

McGraw, K.J. \& Nogare, M.C. (2004): Carotenoid pigments and the selectivity of psittacofulvin-based coloration systems in parrots. Comp. Biochem. Physiol., 138B, 229-233.

Merlin, J.C. (1985): Resonance Raman spectroscopy of carotenoids and carotenoid-containing systems. Pure Appl. Chem., 57, 785792.

Merlin, J.C. \& Delé-Dubois, M.L. (1983): Etude par spectroscopie Raman de résonance de la pigmentation des squelettes calcaires des certains coraux. Bull. Soc. Zool. Fr., 108, 289-301.

—, - (1986): Resonance Raman characterization of polyacetylenic pigments in the calcareous skeleton. Comp. Biochem. Physiol., 84B, 97-103.

Okamoto, H., Saito, S., Tasumi, M., Eugster, C. (1984): Resonance Raman spectra and excitation profiles of tetradesmethyl- $\beta$-carotene. J. Raman Spectrosc., 15, 331-335.

Saito, S. \& Tasumi, M. (1983): Normal coordinate analysis of retinal isomers and assignment of Raman and infrared bands. J. Raman Spectrosc., 14, 236-245.

Saito, S., Tasumi, M., Eugster, C. (1983): Resonance Raman spectra (5800-40 $\left.\mathrm{cm}^{-1}\right)$ of all-trans and 15-cis isomers of $\beta$-carotene in the solid state and in solution. Measurements with various laser lines from ultraviolet to red. J. Raman Spectrosc., 14, 299-309.

Salares, V.R., Young, N.M., Carey, P.R., Bernstein, H.J. (1977): Excited state (excitation) interactions in polyene aggregates. Resonance Raman and absorption spectroscopic evidence. $J$. Raman Spectrosc., 6, 282-288.

Schaffer, H., Chance, R., Silbey, R., Knoll, K., Schrock, R. (1991): Conjugation length dependence of Raman scattering in a series of linear polyenes: Implications for polyacetylene. J. Chem. Phys., 94, 4161-4170.

Schügerl, F.B. \& Kuzmany, H. (1981): Optical modes of transpolyacetylene. J. Chem. Phys., 74, 953-958.

Soldati, A.L., Jacob, D.E., Wehrmeister, U., Häger, T., Hofmeister, W. (2008): Micro-Raman spectroscopy of pigments contained in different calcium carbonate polymorphs from freshwater cultured pearls. J. Raman Spectrosc., 39, 525-536.

Stradi, R., Celentano, G., Rossi, E., Rovati, G., Pastore, M. (1995): Carotenoids in bird plumage-I. The carotenoid pattern in a series of palearctic carduelinae. Comp. Biochem. Physiol., 110B, 131143.

Stradi, R., Pini, E., Celentano, G. (2001a): Carotenoids in bird plumage: the complement of red pigments in the plumage of wild and captive bullfinch (Pyrrhula pyrrhula). Comp. Biochem. Physiol., 128B, 529-535.

-,,$--(2001 \mathrm{~b})$ : The chemical structure of the pigments in Ara macao plumage. Comp. Biochem. Physiol., 130B, 57-63. 
Stradi, R., Rossi, E., Celentano, G., Bellardi, B. (1996): Carotenoids in bird plumage: The pattern in three Loxia species and in Pinicola enucleator. Comp. Biochem. Physiol., 113B, 427-432.

Urmos, J., Sharma, S.K., Mackenzie, F.T. (1991): Characterization of some biogenic carbonates with Raman spectroscopy. Am. Mineral., 76, 641-646.

Veronelli, M., Zerbi, G., Stradi, R. (1995): In situ resonance Raman spectra of carotenoids in bird's feathers. J. Raman Spectrosc., 26, 683-692.
Vershinin, A. (1996): Carotenoids in mollusca: approaching the functions. Comp. Biochem. Physiol., 113B, 63-71.

Withnall, R., Chowdhry, B., Silver, J., Edwards, H., de Oliveira, L. (2003): Raman spectra of carotenoids in natural products. Spectrochim. Acta, 59A, 2207-2212.

Received 31 December 2007

Modified version received 5 August 2008

Accepted 17 September 2008 